\title{
CONFLITOS E OBSTÁCULOS OPERACIONAIS EM GESTÃO DE PROJETOS INOVADORES: UM ESTUDO EMPÍRICO
}

\author{
CONFLICTS AND OPERATIONAL HURDLES IN THE \\ MANAGEMENT OF INNOVATIVE PROJECTS: \\ AN EMPIRICAL STUDY
}

\author{
Recebido 09/05/2012 \\ Aceito 20/10/2012 \\ José Varela Donato ${ }^{1}$ \\ Edson Keyso de Miranda Kubo ${ }^{2}$ \\ Carlos Roberto Domingues ${ }^{3}$
}

\section{RESUMO}

Este artigo objetiva descrever o modo como conflitos e obstáculos operacionais se manifestam em gestão de projetos inovadores em um banco de desenvolvimento (BD). A pesquisa possui uma abordagem qualitativa e exploratória; a coleta de dados foi realizada por meio de entrevistas com consultores e gerentes de projetos e de documentos do Banco de Desenvolvimento sobre gestão de projetos; as entrevistas foram submetidas à análise de conteúdo com uso do software Atlas.ti. Este estudo revelou que a gestão de projetos, em seu novo modelo implantado, depara-se com dificuldades semelhantes àquelas presentes nas hierarquias tradicionais. Observou-se que conflitos relacionados a interesses, valores, aspectos psicológicos e obstáculos operacionais são intrínsecos ao ciclo de vida de projetos inovadores, cuja implantação, para ser eficaz, requer muita capacidade política de seus líderes.

Palavras-chave: gestão de projetos, conflitos, inovação, política.

\footnotetext{
${ }^{1}$ Possui graduação em Ciências Econômicas pela Universidade de Fortaleza - UNIFOR, especialização em MBA Executivo em Finanças pela Universidade Federal do Rio de Janeiro - UFRJ e mestrado em Administração pela Universidade Federal de Santa Catarina - UFSC. Atualmente é superintendente de suporte estratégico do Banco do Nordeste do Brasil. Fortaleza, Ceará, Brasil. E-mail: jvarela@ superig.com.br.

${ }^{2}$ Possui graduação em Administração Pública pela Universidade Estadual Paulista - UNESP, mestrado em Administração pela Kobe University - Japão e doutorado em Administração pela Fundação Getúlio Vargas - FGV. Atualmente é professor na Universidade Municipal de São Caetano do Sul - USCS. São Caetano do Sul, São Paulo, Brasil. E-mail: edsonkubo@uscs.edu.br.

${ }^{3}$ Possui graduação em Pedagogia pela Universidade Tuiuti do Paraná - UTP e em Administração pelo Complexo de Ensino Superior do Brasil, especialização em Administração em Agribusiness pelo Centro de Desenvolvimento Empresarial, mestrado em Administração pela Escuela Superior de Administración y Dirección de Empresas - ESADE e doutorado em Administração pela Fundação Getúlio Vargas - FGV. Atualmente é professor na Universidade Federal de Uberlândia - UFU. Uberlândia, Minas Gerais, Brasil. E-mail: carlosdomingues@yahoo.com.
} 


\section{ABSTRACT}

This article aims at describing how conflicts and operational hurdles manifest themselves in the management of innovative projects in a development bank (DB). The research characterizes itself as a qualitative and exploratory approach; the data collection consisted of interviews with consultants and project managers and by documents on management projects in Development Bank; the interviews have undergone the content analysis by utilizing the Atlas.ti. The research revealed that the project management in its new implemented model faces difficulties similar to those observed in traditional hierarchies. It was observed that conflicts regarding interests, values, psychological aspects and operational hurdles are intrinsic to the life cycle of innovative projects, which implementation requires a lot of political capacity from their leaders to be effective.

Keywords: project management, conflicts, innovation, politics.

\section{INTRODUÇÃO}

A presença de consumidores mais sofisticados e o aumento da rivalidade empresarial expõem às organizações a necessidade de elevar a produtividade do trabalho, crescentemente mais complexo na sociedade do conhecimento (DRUCKER, 2002), em que a criatividade constitui aspecto central da inovação em produtos, serviços e processos, condição determinante para a competitividade e lucratividade das empresas (PORTER, 1993; JULIEN, 2010).

Fatores como crescente complexidade do trabalho, interdependência de funções empresariais e necessidade de maior flexibilidade tornaram evidente que as estruturas hierárquicas tradicionais não estavam adequadas para que organizações pudessem, eficientemente, projetar, produzir e comercializar produtos e serviços de qualidade. Nesse contexto, surgiram nas empresas estruturas paralelas, como equipe de projeto e gestão por projetos (DAFT, 2008; PMI, 2008).

A literatura define o projeto como uma estrutura autônoma, criada com o propósito exclusivo de desenvolver e implantar um novo produto, serviço, processo ou mudança. Seus participantes serão motivados por objetivos desafiadores, visibilidade, oportunidade de aprendizagem e aplicação de seus talentos em um trabalho inovador (PMI, 2008).

O banco de desenvolvimento (BD) esforçou-se para institucionalizar um modelo próprio de gestão de projetos, por ter reconhecido a importância e as dificuldades de desenvolver, com eficácia, projetos inovadores atrelados à hierarquia. Para tanto, definiu objetivos, arcabouço conceitual, instâncias decisórias, processo de gestão, tipologias e classificação de projetos e critérios de formação de equipe do seu modelo de gestão de projetos; treinou funcionários; e criou o escritório de projetos. Apesar dessas medidas, os autores perceberam que os problemas em gestão de projetos vivenciados na hierarquia tradicional parecem persistir no BD. Ademais, observa-se que os manuais de gestão de projetos conferem pouca atenção ao uso do poder e da capacidade política do líder de projetos, manuais esses que, no caso do BD, parecem essenciais. Assim, este artigo pretende responder à seguinte pergunta de pesquisa:

Como se manifestam os conflitos e os obstáculos operacionais percebidos por líderes e consultores no desenvolvimento e na implantação de projetos inovadores no banco de desenvolvimento (BD)?

Nesse sentido, este artigo tem como objetivo identificar, na gestão de projetos inovadores no banco de desenvolvimento, os tipos de conflitos e obstáculos operacionais e a forma como estes se manifestaram em todas as fases do ciclo de vida de projetos, assim como os papéis desempenhados por líderes de projetos.

A exploração das experiências de líderes e consultores de projetos inovadores no BD suscitou vários temas inerentes aos conflitos e obstáculos operacionais. Espera-se que este artigo contribua para elevar o conhecimento no que diz respeito aos tipos de conflitos e obstáculos 
operacionais enfrentados no ciclo de vida da gestão projetos inovadores e aos papéis dos líderes, especialmente os políticos, uma vez que a literatura se concentra nos aspectos técnicos.

Feita essa introdução, este artigo contempla quatro partes subsequentes. O referencial teórico expõe os aspectos centrais da pergunta de pesquisa - conflitos e projetos inovadores e processos de desenvolvimento de projetos. Em seguida, apresentam-se a metodologia, os resultados e, por último, as considerações finais da pesquisa.

\section{REFERENCIAL TEÓRICO}

Esta seção se compõe de dois tópicos: 1) o significado e a origem dos conflitos e o potencial de estes se manifestarem em projetos inovadores; 2 ) conceito de projeto e seus principais processos de desenvolvimento.

\subsection{Conflitos e Projetos Inovadores}

Na vida cotidiana, à medida que intensificam seus relacionamentos, as pessoas experimentam situações de conflito, indesejáveis e portadoras de más lembranças (FERREIRA, 1989):

1. Embate dos que lutam. 2. Discussão acompanhada de injúrias e ameaças, desavença. 3. Guerra. 4. Luta, combate. 5. Colisão, choque.

Chanlat (1996, p. 711) considera tensões e conflitos fenômenos centrais à vida coletiva e à base da ação política; uma necessidade social, à medida que "a transformação política é sempre baseada no conflito", e, ao mesmo tempo, uma doença social, à medida que "a vida política e os choques que ela provoca são frequentemente uma fonte de sofrimento para indivíduos e grupos envolvidos". O conflito nasce quando uma parte "percebe que seus interesses são ou serão afetados negativamente pelos interesses de outros", ou seja, quando "pessoas desejam as mesmas coisas, e o acesso a essas coisas é limitado" (CLEGG; KORNBERGER, PITSIS, 2008, p. 113).

Compostas de complexidade, surpresa, ambiguidade, recursos escassos, redes de pessoas com interesses divergentes e coalizões de indivíduos e grupos, organizações são solo fértil para geração de conflitos e arenas políticas em que metas e decisões resultam do exercício do poder e da política (MORGAN, 1986; BOLMAN; DEAL, 2008; RASCHE; CHIA, 2009).

Inspirado em Weber $(1987,1964)$, para quem a ação social pode ser racional com relação a fins e valores, afetiva ou tradicional, Chanlat (1996) classifica os conflitos organizacionais em três tipos, que podem ocorrer simultaneamente:

- conflitos de interesses - quando interesses, baseados em cálculo racional, entram em choque. Os acionistas procuram maximizar seus dividendos, e a administração, manter o controle; os empregados desejam maiores salários, e os consumidores, melhores produtos;

- conflitos de valores - quando regras ou valores, implícitos ou explícitos, entram em choque. Valores governam relações organizacionais, enfatizam o fundamento normativo da ação e determinam julgamento e conduta;

- conflitos psicológicos ou emocionais - quando personalidades opostas de indivíduos ou grupos se relacionam. Os conflitos podem ser intrapsíquicos (enfatizam tensões internas entre indivíduos) ou interpsíquicos (preocupados com o efeito de estados psicológicos sobre relacionamentos entre líder e grupo ou entre grupos).

Hoje, predomina na literatura a ideia de que conflitos, naturais e inevitáveis nas relações humanas, produzem efeitos positivos e negativos nas organizações (HALL, 2004; BOLMAN; DEAL, 2008; DAFT, 2008; CLEGG; KORNBERGER, PITSIS, 2008) e podem ser resolvidos por meio do 
poder e da política (MORGAN, 1986; PFEFFER, 1994).

Para que líderes exercitem vontade e perícia política com eficácia, importa saber que conflitos são mais frequentes e intensos em decisões que envolvem incerteza e desacordo, níveis hierárquicos mais altos, questões cruciais e domínios em que o desempenho é difícil de avaliar (PFEFFER, 1994).

O poder é usado, frequentemente, em decorrência de conflitos em duas condições destacadas por Pfeffer (1994): na interdependência e na diferença de pontos de vista. A interdependência ocorre quando "um ator não controla inteiramente todas as condições necessárias para a realização de uma ação ou para obter o resultado desejado dessa ação" (PFEFFER; SALANCIK, 2003, p. 40). Dentre as condições requeridas para a ação, escassez de recursos é um fator crítico a influenciar a natureza da interdependência (PFEFFER, 1994). Segundo Pfeffer (1994), a interdependência não será suficiente para exigir o uso do poder se, entre os atores, não houver diferentes pontos de vista sobre metas ou pressupostos, influenciados pela especialização das funções, e diferentes incentivos, bem como falta de clareza de objetivos, de ameaça ou de competitividade externa.

Inovação, incerteza, complexidade e decisões cruciais são integrantes de um projeto e condições estimuladoras de conflitos, que requerem "solução" dos líderes (CLELAND; IRELAND, 2002; VALERIANO, 2005; VARGAS, 2005; RASCHE; CHIA, 2009). No Quadro 1, explicitam-se condições identificadas por Zaltman, Dunkan e Holbek (apud HALL, 2004) que tornam difícil a implantação de inovações e, consequentemente, de projetos inovadores.

\begin{tabular}{|c|c|c|}
\hline RECURSOS & PROCESSOS & $\begin{array}{l}\text { RESULTADOS } \\
\text { PERCEBIDOS }\end{array}$ \\
\hline $\begin{array}{l}\text { - Conhecimento científico } \\
\text { insuficiente. } \\
\text { - Complexidade elevada. } \\
\text { - Custos econômicos e sociais } \\
\text { percebidos como elevados. } \\
\text { - Credibilidade insuficiente do } \\
\text { proponente. } \\
\text { - Compromisso insuficiente dos } \\
\text { interessados. }\end{array}$ & $\begin{array}{l}\text { - Comunicação deficiente. } \\
\text { - Irreversibilidade e dificuldade } \\
\text { de alterações da inovação. } \\
\text { - Envolvimento grande na } \\
\text { tomada de decisão. }\end{array}$ & $\begin{array}{l}\text { - Retorno do investimento } \\
\text { baixo. } \\
\text { - Resultados não claros. } \\
\text { - Risco elevado. } \\
\text { - Choque com práticas atuais, } \\
\text { tidas como mais eficientes. } \\
\text { - Mudança prejudicial às } \\
\text { relações interpessoais. }\end{array}$ \\
\hline
\end{tabular}

Quadro 1 - Algumas condições que dificultam a implantação de uma inovação

Fonte: elaboração própria, com base em HALL (2004).

Um projeto inovador pode incorporar outros elementos que aumentam as possibilidades de ocorrência de conflitos em sua gestão, principalmente quando sua equipe se impregna de forte sentimento de grupo (VALERIANO, 2005). Além do caráter temporário do projeto (em uma organização permanente) e da dupla subordinação dos membros da equipe (à hierarquia e ao líder do projeto), conflitos são derivados de divergências: entre os objetivos do projeto e os da organização; entre os valores dos participantes do projeto e os da hierarquia; e em relação a métodos de gestão do projeto, prioridades, agendamentos dos trabalhos, personalidades, formações de equipes com pessoal de outras áreas, estimativas de custos e avaliações técnicas e de desempenho (CLELAND; IRELAND, 2002; VALERIANO, 2005; VARGAS, 2005; KERZNER, 2006).

Por fim, conflitos e obstáculos na implantação de uma inovação dependem, também, de características da organização, tais como cultura, coalizões, estrutura, formalização, estratégia, capacitação dos membros, dentre outros fatores (HALL, 2004; JANOWICZ-PANJAITAN; NOORDERHAVEN, 2009; SILVA; GONÇALVES, 2011). 


\subsection{Conceito e Processos de Desenvolvimento de Projeto}

Cleland e Ireland (2002) indicam o surgimento da disciplina de gestão de projetos na década de 1950, na indústria de construção e, mais recentemente, na área de materiais bélicos. Hoje, considera-se importante a excelência em gestão de projetos para a competitividade e o desempenho empresarial: projetos geram novos produtos, serviços e meios eficientes para atender os clientes, proporcionam o crescimento, viabilizam a estratégia e criam mudança organizacional (GRAHAM; ENGLUND, 1997; BARNEY; WRIGHT; KETCHEN, 2001; PMI, 2008).

Incorporado ao linguajar cotidiano de organizações, o conceito de projeto, com pequenas variações de suas características estruturais, é retratado pela literatura, conforme a Figura 1.

$\mathrm{Na}$ ideia de projeto inovador, três atributos imbricados sobressaem: inovação, complexidade e incerteza. Um projeto gera novo produto, serviço ou processo (PFEIFFER, 2005); a complexidade expressa-se na necessidade de múltiplos conhecimentos; e a incerteza, na dificuldade de mensurar seus resultados (LINDBLOM, 1959; MAXIMIANO, 2006; WYSOCKI, 2009). Esses atributos exigem criatividade e tornam mutável a especificação da funcionalidade e qualidade de um projeto inovador (MINTZBERG, 1978; WYSOCKI, 2009), conferindo-lhe uma característica importante que é a elaboração progressiva: o escopo do projeto desenvolve-se de maneira incremental (PMI, 2008), definindo-se à medida que avança.

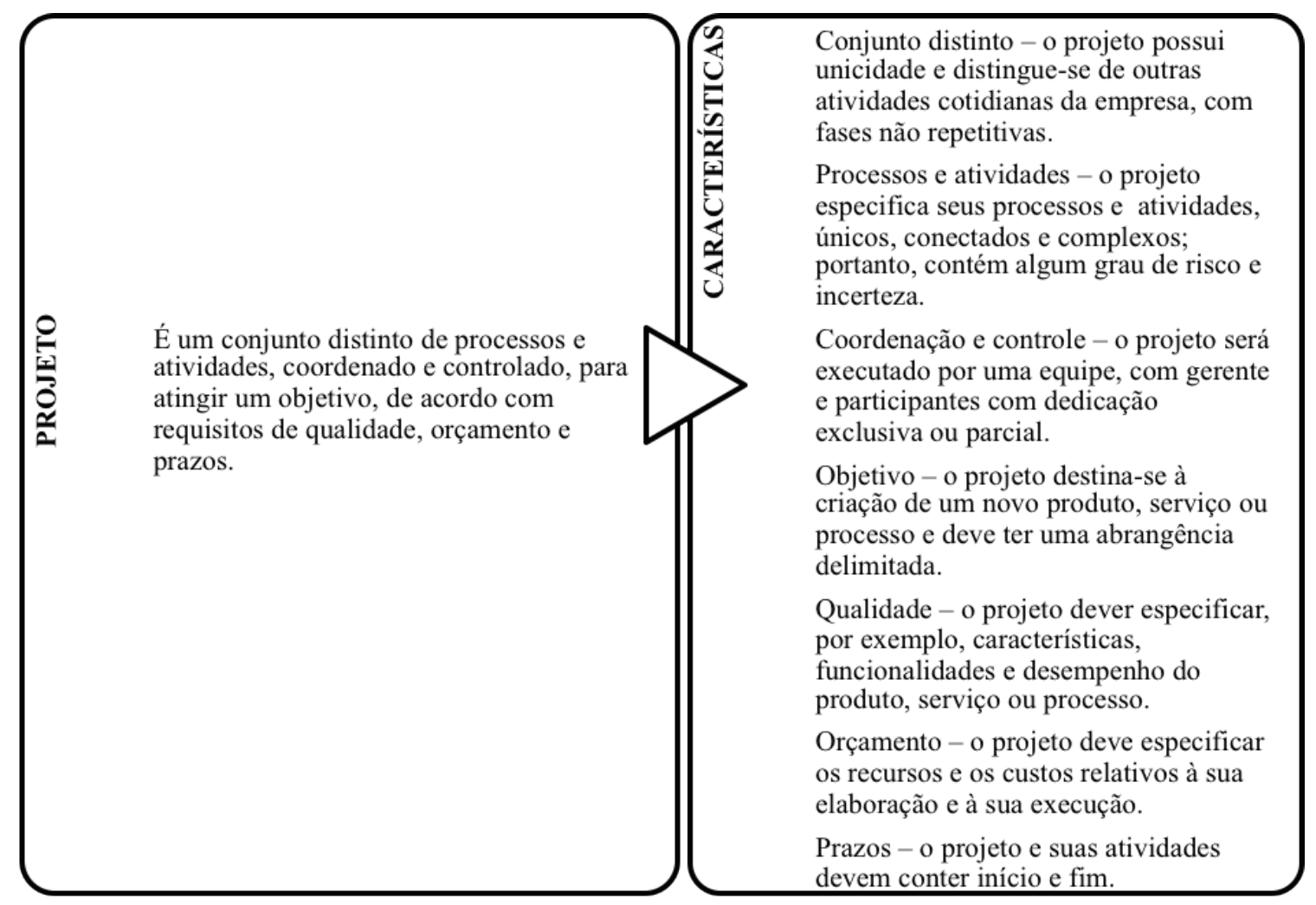

Figura 1 - Conceito de projeto e suas características estruturais

Fonte: elaboração própria, com base em ISO 10006 (2003), Carvalho, Abreu e Pedroso (2013), Pfeiffer (2005), Vargas (2005), Kerzner (2006), Gido e Clementes (2007), PMI (2008) e Wysocki (2009).

Um projeto é executado com limitações de custo e tempo, parâmetros para avaliação do grau de eficiência de sua gestão. Por isso, entende-se que projetos de alta qualidade devem funcionar com restrição equilibrada de escopo, custo e tempo (PMI, 2008; WYSOCKI, 2009; DU- 
ARTE; BIANCOLINO; STOROPOLI; RICCIO, 2012).

\begin{tabular}{|c|c|c|c|}
\hline $\begin{array}{l}\text { G1. Processos de } \\
\text { Iniciação }\end{array}$ & $\begin{array}{l}\text { G2. Processos de } \\
\text { Planejamento }\end{array}$ & $\begin{array}{l}\text { G3. Processos de } \\
\text { Execução }\end{array}$ & $\begin{array}{l}\text { G5. Processos de } \\
\text { Encerramento }\end{array}$ \\
\hline $\begin{array}{l}\text {-Definir projeto } \\
\text {-Designar líder } \\
\text {-Definir escopo inicial } \\
\text {-Definir interessados }\end{array}$ & $\begin{array}{l}\text {-Definir escopo: bene- } \\
\text { fícios, objetivos e ativi- } \\
\text { dades } \\
\text {-Definir equipe } \\
\text {-Elaborar planos } \\
\text {-Elaborar orçamento }\end{array}$ & $\begin{array}{l}\text {-Liderar } \\
\text {-Gerenciar execução } \\
\text {-Realizar aquisições } \\
\text {-Gerenciar qualidade } \\
\text {-Gerenciar expectativas }\end{array}$ & $\begin{array}{l}\text {-Finalizar atividades } \\
\text {-Finalizar aquisições } \\
\text {-Documentar lições }\end{array}$ \\
\hline \multicolumn{4}{|c|}{ G4. Processo de Monitoração e Controle } \\
\hline \multicolumn{4}{|c|}{$\begin{array}{l}\text { Controlar o trabalho - Realizar controle das mudanças - Verificar escopo } \\
\text { mento, qualidade, riscos, aquisições e desempenho }\end{array}$} \\
\hline \multicolumn{4}{|c|}{ Quadro 2 - Processos principais de gestão de projetos em cinco grupos } \\
\hline \multicolumn{4}{|c|}{ Fonte: adaptado de PMI (2008). } \\
\hline
\end{tabular}

Para o Project Management Institute-PMI (2008, p. 8), a gestão de projetos consiste na "aplicação de conhecimento, habilidades, ferramentas e técnicas para projetar atividades que satisfaçam as especificações do projeto" e compreende grupos de processos inter-relacionados, como mostra o Quadro 2. Vale ressaltar que esses processos de gestão de projetos requerem mudanças de cultura, técnicas, fluxo de informação, modelo gerencial e regras de poder e originam conflitos (WEICK, 1995; CARVALHO; RABECHINI Jr., 2006).

Diante dos desafios da gestão de projetos e da importância de seu aspecto político, torna-se justificável a pesquisa acerca de uma organização em que a capacidade políticas dos líderes de projetos para lidar com os conflitos se revelou um requisito essencial, contrariando manuais de projetos que lhe conferem pouco importância. A próxima seção apresentará a metodologia desta pesquisa.

\section{METODOLOGIA}

Esta pesquisa utilizou uma abordagem qualitativa e exploratória com o objetivo de captar a percepção sobre conflitos e obstáculos operacionais por consultores e gerentes na implantação de projetos inovadores em um banco de desenvolvimento (BD).

\subsection{Abordagem Metodológica}

A abordagem qualitativa neste artigo justifica-se porque o estudo busca compreender, segundo a perspectiva dos gerentes e consultores de projetos, o significado e a singularidade de conflitos e obstáculos percebidos em meio a interações sociais complexas, desenvolvidas no ciclo de vida de projetos inovadores. Em pesquisa qualitativa, os dados são constituídos de textos originados de múltiplas fontes, e a interpretação representa o elemento crucial de análise (CRESWELL; CLARK, 2007).

Como um estudo de caso, investiga-se empiricamente um fenômeno contemporâneo de maneira holística e intensiva, junto a pessoas que compartilharam da experiência como gerentes e consultores de projetos no BD (YIN, 2005; GIL, 2009). 


\subsection{Coleta e Análise dos Dados}

A pesquisa valeu-se de gerentes e consultores de projetos inovadores e de normas do BD sobre gestão de projetos como fontes de dados. Principal método usado para captar a percepção de líderes e consultores de projeto inovadores sobre a pergunta de pesquisa, a entrevista oferece vantagem quando se lida com questões complexas e perguntas abertas (HAIR et al., 2005) e se buscam descobrir aspectos de determinada experiência (RICHARDSON, 1999), bem como obter respostas profundas e detalhadas (COOPER; SCHINDLER, 2003).

A escolha dos gerentes e consultores internos de projetos do BD ocorreu de maneira intencional, com base em sua participação em, pelo menos, dois projetos inovadores. Os entrevistados aceitaram gravar ou descrever suas experiências, desde que lhes fosse preservado o anonimato. Assim, realizaram-se cinco entrevistas, especificadas no Quadro 2, centradas em torno do desenvolvimento e da implantação de projetos inovadores, definidos pelas normas do $\mathrm{BD}$ como aqueles com graus mais elevados de inovação, contribuição para resultados, retorno financeiro, risco e de abrangência organizacionais.

\begin{tabular}{|c|c|c|c|c|c|}
\hline Tipos & Entrevistados & Escolaridade & Experiência & $\begin{array}{c}\text { Tempo de } \\
\text { gravação }\end{array}$ & $\begin{array}{c}\text { Páginas } \\
\text { transcritas }\end{array}$ \\
\hline \multirow{2}{*}{$\begin{array}{c}\text { Entrevistas } \\
\text { face a face }\end{array}$} & Funcionário & $\begin{array}{c}\text { Pós-graduação } \\
\text { lato sensu }\end{array}$ & $\begin{array}{c}\text { Líder de 3 projetos ino- } \\
\text { vadores }\end{array}$ & 1 h12min & 14 \\
\cline { 2 - 6 } & Funcionário & $\begin{array}{c}\text { Pós-graduação } \\
\text { lato sensu }\end{array}$ & $\begin{array}{c}\text { Consultor em projetos } \\
\text { estratégicos }\end{array}$ & 1 h17min & 16 \\
\cline { 2 - 6 } & $\begin{array}{c}\text { Consultor ex- } \\
\text { terno }\end{array}$ & Doutorando & $\begin{array}{c}\text { Líder de projetos inova- } \\
\text { dores }\end{array}$ & 29 min & 4 \\
\hline \multirow{2}{*}{$\begin{array}{c}\text { Entrevistas } \\
\text { por e-mail }\end{array}$} & Funcionário & Mestrado & $\begin{array}{c}\text { Líder de 2 projetos ino- } \\
\text { vadores }\end{array}$ & - & 3 \\
\cline { 2 - 7 } & Funcionário & Mestrado & $\begin{array}{c}\text { Líder de 3 projetos ino- } \\
\text { vadores }\end{array}$ & - & 1 \\
\hline
\end{tabular}

Quadro 3 - Especificação das entrevistas

Nas entrevistas face a face, o problema de pesquisa foi exposto para que cada entrevistado narrasse sua experiência como líder ou consultor de um projeto inovador no BD. À medida que o entrevistado falava, solicitava-se que ele explicitasse como conflitos e obstáculos se manifestaram e como ele procurou superá-los. Dois gerentes de projetos foram entrevistados por e-mail, uma forma diferente da entrevista realizada pessoalmente (FLICK, 2009); esses entrevistados foram informados, por telefone, dos objetivos e do problema da pesquisa; em seguida, por e-mail, o problema da pesquisa foi novamente expresso, e solicitou-se a eles que descrevessem sua experiência como líder de um projeto inovador.

A análise dos dados e a narração dos resultados representaram passos cruciais para responder ao problema de pesquisa. Primeiramente, as entrevistas transcritas foram submetidas à análise de conteúdo, uma "técnica de pesquisa para fazer inferências replicáveis e válidas de textos para os contextos em que foram utilizados" (KRIPPENDORF, 2004, p. 18). Após, procedeu-se à análise temática das entrevistas (BARDIN, 2008), de acordo com os seguintes temas previamente definidos, vinculados aos cinco grupos de processos de gestão de projetos detalhados na Figura 2 (Iniciação, Planejamento, Execução, Monitoração e Controle e Encerramento):

- conflitos - são choques de interesses, de valores ou de personalidades entre pessoas ou grupos (CHANLAT, 1996); 
- obstáculos operacionais - são dificuldades enfrentadas no planejamento, na definição de processos, na obtenção de recursos e em sistemas de apoio ao projeto, dentre outras.

Assim, a codificação temática das entrevistas foi elaborada com uso do software Atlas. ti, de acordo com os seguintes passos:

- cadastro dos processos de gestão de projetos e dos temas no software Atlas.ti;

- seleção dos segmentos dos textos, vinculando-os aos processos de gestão de projetos e aos temas pertinentes;

- listagem do relatório de codificação, que consiste nos segmentos dos textos das entrevistas, classificados segundo os processos de gestão de projetos e, dentro destes, por tema.

Com base nos resultados da codificação temática supracitada, elaborou-se a narrativa dos resultados, segmentada de acordo com os processos de gestão de projetos. Conforme sugere a pesquisa qualitativa, a narrativa mesclou a interpretação dos pesquisadores com citações e vocabulário dos entrevistados (YIN, 2005; CRESWELL; CLARK, 2007).

\section{RESULTADOS DA PESQUISA}

Nesta seção, são expostos os conflitos e obstáculos percebidos pelos líderes e consultores de projetos inovadores entrevistados no $\mathrm{BD}$, nos grupos de processos de gestão de projetos definidos pelo PMI (2008), explicitados na Figura 2. Embora os entrevistados não tenham se expressado segundo os processos do PMI (2008), a codificação das entrevistas foi facilitada em razão do conhecimento dos autores sobre os projetos inovadores reportados.

\subsection{Processos de Iniciação}

"Era a menina dos olhos do presidente". Um projeto inovador, com possibilidade de obtenção de visibilidade e bons resultados para a empresa, segundo um entrevistado, desperta, na equipe, "paixão", entusiasmo e sentimento de ser "agente de transformação" e conquista o apoio da direção do BD e de outros tomadores de decisão importantes.

"Aquilo que faltava, estava chegando, não tem por que não ser apoiado". Assim, os membros de uma equipe, de início, pensaram ser pacífica a aceitação de um projeto inovador com potencial de agregar atividades e benefícios, porque, embora atacasse valores e comportamentos arraigados, não concorria com outras atividades do BD.

"Agora, bote aí para funcionar, para a gente ver se funciona mesmo". Entretanto, uma ideia inovadora é ambígua: por um lado, encanta e gera expectativas, dá, inclusive, uma impressão de que "todos estão de acordo com ela"; por outro lado, ela vem embalada com incertezas sobre resultados e modo de funcionamento, um "ver para crer", e com um apoio fraco da direção da empresa e dos principais tomadores de decisão (HALL, 2004).

A gestão de uma empresa, quando ela valida um projeto desses, ela faz acima de tudo uma aposta. Se der certo, ótimo! Se não der certo, não tem problema. A gente desarruma tudo e as pessoas ficam talvez uns fracassados [...] $\mathrm{O}$ apoio dele [presidente] era um apoio 'ok, isso é um negócio bom. Agora, bote aí para funcionar...'. 
"O gerente do projeto fica sem apoio". No BD, a escolha do líder, uma decisão importante, ocorre no início da criação do projeto. Os gerentes lutam para indicar o líder de um projeto relacionado com suas áreas, condição que os coloca como "parceiros da inovação", Ihes dá conhecimento ou controle sobre mudanças que possam atingi-los direta e futuramente e amplia seus espaços de poder. Segundo um dos entrevistados, quando a hierarquia arbitra esses embates, o líder de projeto designado fica sem apoio e credibilidade, principalmente quando não é especialista no tema; e "quando não há disputa e a hierarquia superior (presidente) define a questão sem ouvir, o resultado pode ser o mesmo".

"Um projeto órfão que certamente fracassará". Dessa forma expressou-se um entrevistado sobre um projeto com patrocinador "apenas no papel", que não "compra" a ideia, não deseja sua implantação ou não participa das decisões críticas. No BD, a supervisão de um projeto inovador fica a cargo de um patrocinador, que, prestigiado, representa uma condição necessária, mas não suficiente para o sucesso do projeto.

Nos processos de iniciação, pôde-se observar que projetos inovadores se deparam com obstáculos de natureza operacional, decorrentes da dificuldade de expressar com clareza seus resultados, dadas as incertezas que o envolvem (HALL, 2004). Além disso, surgem conflitos, originados por sinalização de mudanças em valores organizacionais, busca de visibilidade, controle de mudanças e proteção de espaços de poder (CHANLAT, 1996; CLEGG; KORNBERGER; PITSIS, 2008).

\subsection{Processos de Planejamento}

"Às vezes, eu me preocupo se existe um escopo". A magnitude da inovação parece ser um grande obstáculo à definição operacional de escopo, de objetivos e de atividades de um projeto, como requer o guia do PMI (2008). Na visão de um dos entrevistados, a inovação é um processo de descoberta, cujo caminho será revelado na prática, na experimentação. A definição do escopo envolve, portanto, um problema técnico e um problema político, cujas soluções exigem criatividade e habilidade para negociar eventuais mudanças.

E aí é que está a dificuldade, porque você tem que renegociar escopo, renegociar apoios, é outro projeto, essa é outra dificuldade, até que ponto terminou um e aqui já é outro projeto. Precisa ter muita sabedoria [...] Posso dizer que foi o maior [obstáculo] nosso [...] Você pode fazer uma EAP do projeto [...], mas às vezes você não vai saber o desdobramento daquilo [...] é o desconhecimento mesmo. A inovação é o campo para estar mais aberto para experimentação [...] você apenas vai botar as pessoas dentro de uma sala, e elas vão sair e fabricar uma coisa pronta como já tivesse um "bê-á-bá" aí para fazer, e não é.

“Devagar com o andor, porque o santo é de barro!". Evidenciar oportunidades de melhorias no escopo e nas atividades do projeto (não vistas ou aproveitadas pela hierarquia) desencadeia lutas para proteger espaços de poder, com reflexo na amplitude e profundidade de mudanças, porque "projetos estratégicos não ocorrem num vácuo organizacional", como diz um entrevistado. Reduzir o escopo do projeto, empobrecendo-o, e frear o ímpeto da equipe são atitudes observadas e vistas, também, como demonstração de "ciúme".

Como normalmente existem interdependências entre propostas de mudança de grande magnitude e as hierarquias, a saída é 'baixar a bola' dessa rapaziada, pauperizar o projeto: 'não é possível desenvolver e implantar tamanha mudança agora, precisaríamos rever muitas coisas', 'vamos colocar os pés no chão', 'não temos recursos suficientes', 'devagar com o andor, porque o santo é de barro!. 
“Projeto catedral”. Às vezes, o desenho e a execução de um projeto são tarefas paradoxais: por um lado, o projeto enfrenta o risco de redução de seu potencial inovador por lutas internas ou "ciúmes"; por outro lado, o projeto também corre o risco de ampliação, a ponto de tornar-se inadministrável, se não tiver um patrocinador forte para "barrar" algumas mudanças.

"Qual é mesmo o resultado que esse projeto vai dar?". Um entrevistado afirma que o BD possui uma cultura orientada para resultados em curto prazo, medidos quantitativamente, e para controlar comportamentos. Assim, um projeto gerou percepções diferentes sobre sua relevância, seu descrédito e sua falta de aceitação, porque seus resultados eram em longo prazo, intangíveis e difíceis de medir e, ainda, o porque exigiu mudança de mentalidade e de estilo de liderança da empresa.

Eu acho que isso era um ponto crucial [...] Porque, como são inovações, às vezes, esse resultado não é percebido [...] e nem todo mundo vê o mesmo resultado, e nem valida [...] Se eu estou fazendo uma inovação, que a pessoa não fica mais nem dentro da agência [...] ele está fazendo outro trabalho, que não tem nada muito concreto para medir, que o que tem de resultado não é monetizado [...] É tão intangível a ação [...] Isso é o quê? Eu acho que tem duas vertentes nisso. Um certo descrédito [...] e uma certa necessidade de apresentar resultados, coisas que pudessem ser mensuráveis quantitativamente [...] Porque a cultura do BD é que o nosso resultado é volume de aplicações.

"O grande time". O líder de projeto inovador, para formar uma equipe multidisciplinar e interfuncional, depende de pessoas fornecidas pela estrutura hierárquica. A escassez de recursos cria obstáculos para obtenção de pessoas com qualificação e dedicação exclusiva, sem as quais "o projeto certamente fracassará". Assim, diz um entrevistado com ironia:

Nessa ocasião, o gerente do projeto vai ouvir dos gerentes hierárquicos: 'no momento, não podemos ceder ninguém ao projeto, pois estamos assoberbados', 'fulano não pode ir, é imprescindível agora' [...] Mas [...] esta é também uma boa oportunidade de os gerentes se livrarem de pessoas que não querem mais em sua área [...] por baixo desempenho, incompatibilidade [...] Até que se forme 'o grande time'.

Novamente, pôde-se ver que, nos processos de planejamento, como definição detaIhada do escopo do projeto, obstáculos operacionais misturam-se com conflitos, que exigem do gerente de projetos capacidade política para obter recursos, negociar mudanças no escopo e administrar manifestações de ciúme de interessados no projeto. Observou-se que um projeto inovador é afetado pela incerteza quanto aos seus resultados, pelo fraco apoio da direção da empresa e pela falta de compromisso com recursos (HALL, 2004), esta decorrente de controle hierárquico, de ciúmes ou de percepção de ameaça a espaços de poder (CLEGG; KORNBERGER; PITSIS, 2008). Evitam-se, também, ameaças de mudanças em valores (CHANLAT, 1996) que, às vezes, um projeto busca promover.

\subsection{Processos de Execução}

"Construir a viabilidade até a implantação". A gestão de um projeto inovador envolve muitas decisões, com obstáculos do começo ao fim, cuja superação requer dos líderes, segundo um dos entrevistados, convicção, entusiasmo e capacidade para "olhar o ambiente". Requer, ainda, "construir a viabilidade até a implantação", porque "não tem nenhuma inovação que nasça viável".

"Um rei sem trono". No BD, o poder dos gerentes hierárquicos parece prevalecer sobre o poder dos líderes de projeto. Para um entrevistado, "um rei sem trono" reflete essa condição do líder do projeto, que, sem a mesma força e a mesma autonomia dos gerentes hierárquicos 
(CLELAND; IRELAND, 2002; VALERIANO, 2005; VARGAS, 2005; KERZNER, 2006), precisa de capacidade política para vencer resistências.

Então, o gerente de projeto acorda para a realidade e vê que as promessas de autonomia, de poder e de desejo de mudança com a criação do projeto são um tanto ilusórias. A capacidade de levar adiante inovações estratégicas, que permeiam a empresa, está limitada à vontade da hierarquia.

"Finalmente, os diretores começaram a botar a atenção nos detalhes". Entrevistados afirmam que o teste definitivo para o sucesso de um projeto ocorre na "implantação", quando os tomadores de decisão enxergam com clareza as consequências do projeto (mudanças de valores, mudanças na "forma de fazer", estabelecimento de compromisso com recursos) e começam a "perceber que é para valer". Se conflitos surgem ou não há envolvimento dos interessados, modificações drásticas comprometem o trabalho já realizado e atrasam a execução do projeto.

"O grande muro". Um entrevistado explica que um projeto inovador somente alcança sucesso se ele é absorvido em termos de cultura, sistemas e processos (KOTTER, 1997; SCHEIN, 2004) e se gera conflitos: agrega nova função na missão do BD, novo trabalho nas agências, nova forma de relacionamento com o público (fora da agência, nas comunidades), novo estilo de liderança (supervisão mais frouxa) e nova avaliação (objetivos intangíveis), requerendo, consequentemente, adaptações na cultura da empresa. Daí, conflitos e dificuldades manifestaram-se, através de resistência declarada ou oculta, desconfiança, desqualificação, descrença, indiferença, insensibilidade e de "não mexer em nada do que existe" (HATCH, 1997).

E aí não mexe nada em sistema, os processos não se desenvolvem. Para mim, esse é o grande muro [...] Mas aquela ideia, ela não desceu em nível de cultura [...] de parcerias [...] de processos [...] de sistemas [...] Mas é assim mesmo. A gente desenhava os formulários para ser a coisa do sistema, mas ele: 'não, mas é muito complicado'. E pronto, abortou [...] O gerente era acostumado a ver o funcionário dele trabalhando. Então, como é que ele ia saber se a pessoa estava trabalhando, estava passeando, se aquela articulação era só conversa fiada, se aquilo ia dar algum resultado?.

"E aí, isso parece que exacerba os olhares, de certa forma um ciúme". Um entrevistado é enfático quanto à necessidade de o líder saber lidar com manifestações explícitas e camufladas de "ciúme": "ciúme" de resultados alcançados e potenciais, "ciúme" de recompensas, "ciúme" de relacionamentos, "ciúme" de visibilidade. Alguns sentimentos relatados pelos entrevistados como "ciúme" aproximam-se da ideia de "inveja" (TOMEl, 1994).

E tem uma manifestação de ciúmes que essa é a mais cruel. Que é em cima de quem está fazendo [...] funcionário mais vigiado [...] que não pode errar [...] ciúmes porque ganha mais, porque precisa viajar, e ganha diária [...] fala com o prefeito, com as instituições [...] 'ele agora é o cara mais importante do banco, nesse município, nessa agência' [...] De boicotar, de falar mal, de botar lente de aumento em cima dos erros, de querer que uma função se acabe. E como é que isso se manifesta? Excesso de carga de trabalho [...] Então, para mim, isso é um grande indício de ciúmes, você quer minimizar. Dizer: 'não, isso aí está muito frágil ainda, isso aqui não dá para implantar, não dá para desenvolver ainda um sistema com isso'.

"Quanto mais criativas e inovadoras, menos se prendem a convenções". A necessidade de contar com pessoas criativas - reconhece um entrevistado - torna o conflito latente nos processos de relacionamento e comunicação de um projeto. O líder deve proporcionar à equipe um ambiente de liberdade para exercício da criatividade e possuir capacidade de solucionar con- 
flitos, através do diálogo, para manter o projeto viável e a equipe coesa.

Nos processos de execução de projetos inovadores, observou-se a presença de obstáculos operacionais, diante das dificuldades de antecipar atividades, recursos e resultados, de obter recursos humanos para compor equipe e de criar sistemas para apoiar mudanças. Em segundo lugar, além de conflitos internos nas equipes, emergiu choque entre mudanças propostas em projetos inovadores e valores sustentados pela empresa.

Observou-se, também, nesta fase de execução de projetos inovadores, devido ao controle rígido da hierarquia, a ausência de legitimidade dos líderes de projetos inovadores no BD (CLELAND; IRELAND, 2002; VALERIANO, 2005; VARGAS, 2005; KERZNER, 2006), que se sentem como um "rei sem trono". Os projetos inovadores enfrentam barreiras culturais, pois requerem mudanças, obstadas por gerentes, no comportamento da organização (KOTTER, 1997; SCHEIN, 2004). Os diretores também atrasam os projetos que consideram ameaçadores por meio da observação de detalhes na execução, tentando neutralizá-los (HATCH, 1997). Observou-se nos resultados da análise a presença de ciúmes de visibilidade e recompensas financeiras ou psicológicas obtidas pelos líderes de projetos (TOMEI, 1994). Conflitos na equipe de projetos também se evidenciam e geram desafios para a liderança, para que mantenham a equipe coesa e gerenciem os egos dos membros criativos.

\subsection{Processos de Monitoração e Controle}

Etapa bem desenvolvida na gestão de projetos, o controle permeia todas as fases do projeto, sem o qual, diz um entrevistado, "o resultado pode ser, pedir uma coisa e receber outra". No caso do projeto $X$, os resultados intangíveis foram aferidos qualitativamente mediante descrição de "casos de sucesso".

"No olho do furacão". As ferramentas de gestão de projeto facilitam o controle, mas transformam o líder no centro das atenções e cobranças de toda a empresa, porque as ineficiências de gestão - bom motivo para implantação da gestão por projetos - tornam-se transparentes, gerando pressão e excessiva carga de trabalho para a equipe.

Quando o projeto diz respeito, por exemplo, ao lançamento de um produto, à criação de um software, às pressões sobre o gerente de projeto são enormes e este fica "no olho do furacão", tendo de explicar, em cada reunião da alta administração, possíveis atrasos.

"É aquela coisa de tentar minimizar". Quando um projeto começa a apresentar bons resultados, o líder do projeto deve estar atento para reconhecer a ajuda da hierarquia e compartilhar com ela os resultados (PFEFFER, 1994). Se isso não ocorre oportunamente, vem o "ciúme", que pode prejudicar apoio futuro.

[...] tem o ciúme dos resultados que você está alcançando. E diz: 'ah, mas está aí porque também a gente ajudou, é porque quem está fazendo isso também são os técnicos da área fulano e fulano, que deram aqui o suporte para eles desenvolverem esse treinamento, essa reunião'.

\subsection{Processos de Encerramento}

"Está bom!" “Vamos pegar de volta". Podem emergir discordâncias entre equipe do projeto e hierarquia quanto à conclusão do projeto, cujos processos precisam ser incorporados à estrutura formal. De um lado, a equipe do projeto quer mostrar sua "missão cumprida", entregando o projeto concluído; de outro, segundo um dos entrevistados, a hierarquia quer absorver logo as atividades, 
devido à necessidade de ampliar espaços de poder ou à presença de "ciúme" da equipe do projeto.

Mas chega um certo ponto que a direção do BD diz: 'Está bom! Você já tem o projeto ' $X$ ' em todas as agências, já está implantado o projeto' [...] Eu acho que os projetos têm esse problema, eles acabam às vezes porque não conseguem fazer a implantação completa. [...] o nosso projeto [...] começou a tocar em coisas muito importantes, que era o planejamento do trabalho no município. Então, isso era grande, isso envolvia externo [...] 'espera aí, vamos pegar de volta'.

"E agora, José?". No BD, o sucesso de um projeto inovador não traz recompensas imediatas para a carreira dos membros da equipe, que devem voltar às suas unidades de origem quando o projeto se encerra. Às vezes, os conflitos entre equipe do projeto e hierarquia ocorridos durante o seu desenvolvimento produzem consequências traumáticas.

Mas as turbulências com a hierarquia enfrentadas no meio do caminho também deixam sequelas. E, por conta disso, às vezes, tal retorno não é mais possível. E agora, José?

"O maior prazer". Apesar dos conflitos e obstáculos enfrentados no desenvolvimento e na implantação de projetos inovadores, estes proporcionam grande satisfação aos membros da equipe, pois geram aprendizagem e recompensas emocionais, individuais e coletivas:

Eu acho que o maior prazer era a sensação de estar construindo uma coisa importante, uma coisa que ia fazer a diferença [...] um trabalho realmente inovador, transformador. E isso dá uma satisfação imensa. A gente trabalha muito além do tempo. Acaba que fica uma irmandade naquela equipe, porque a gente está vivendo aquele sentimento de estar trabalhando em uma transformação. Isso aí é fantástico, é indizível esse sentimento, essa sensação.

\begin{tabular}{|c|c|}
\hline $\begin{array}{l}\text { GRUPOS DE PROCESSOS (G1 A G5) } \\
\text { E EXPRESSÕES MARCANTES }\end{array}$ & FONTES DE CONFLITOS E DE OBSTÁCULOS OPERACIONAIS \\
\hline $\begin{array}{l}\text { G1: Definir projeto. Designar líder do } \\
\text { projeto. } \\
\text { Aquilo que faltava [...], não tem por } \\
\text { que não ser apoiado. Agora, bote aí } \\
\text { para funcionar, para a gente ver se } \\
\text { funciona mesmo. O gerente do pro- } \\
\text { jeto fica sem apoio. Um projeto órfão } \\
\text { que certamente fracassará. }\end{array}$ & $\begin{array}{l}\text { Conflitos de valores e interesses } \\
\text { Possíveis mudanças de valores e comportamentos. } \\
\text { Obter visibilidade, controle das mudanças e ampliação do espaço } \\
\text { de poder. } \\
\text { Obstáculos operacionais } \\
\text { Incertezas sobre resultados. Como funciona? } \\
\text { Falta de envolvimento do patrocinador em questões críticas, pelo } \\
\text { menos. }\end{array}$ \\
\hline $\begin{array}{l}\text { G2: Definir escopo e equipe do pro- } \\
\text { jeto. } \\
\text { Âs vezes, eu me preocupo se existe } \\
\text { um escopo. Devagar com o andor, } \\
\text { porque o santo é de barro! Projeto ca- } \\
\text { tedral. Qual é mesmo o resultado que } \\
\text { esse projeto vai dar? O grande time. }\end{array}$ & $\begin{array}{l}\text { Conflitos de valores e interesses e psicológicos } \\
\text { Relevância do projeto. Cultura orientada para medir resultados } \\
\text { tangíveis } x \text { resultados intangíveis em longo prazo do projeto. } \\
\text { Proteger espaço de poder. "Ciúme" de ideia nova. } \\
\text { Obstáculos operacionais } \\
\text { Incerteza e complexidade da inovação: dificuldades de detalhar } \\
\text { escopo. } \\
\text { Paradoxo: estreitar } x \text { ampliar o escopo. } \\
\text { Obter compromisso com aporte de recursos. }\end{array}$ \\
\hline
\end{tabular}




\begin{tabular}{|c|c|}
\hline $\begin{array}{l}\text { GRUPOS DE PROCESSOS (G1 A G5) } \\
\text { E EXPRESSÕES MARCANTES }\end{array}$ & FONTES DE CONFLITOS E DE OBSTÁCULOS OPERACIONAIS \\
\hline $\begin{array}{l}\text { G3: Gerenciar a execução. Liderar. } \\
\text { Um rei sem trono. Quanto mais criati- } \\
\text { vas e inovadoras, menos se prendem } \\
\text { a convenções. Finalmente, os direto- } \\
\text { res começaram a botar a atenção nos } \\
\text { detalhes. O grande muro. E aí, isso } \\
\text { parece que exacerba os olhares, de } \\
\text { certa forma um ciúme. }\end{array}$ & $\begin{array}{l}\text { Conflitos de valores e interesses e psicológicos } \\
\text { Autonomia do líder x cultura hierárquica predominante. } \\
\text { Liberdade e criatividade para inovação. } \\
\text { Valores e interesses conflitantes; mudanças na estrutura de po- } \\
\text { der. } \\
\text { Cultura orientada para medir resultados tangíveis x resultados } \\
\text { intangíveis em longo prazo do projeto; supervisão próxima x su- } \\
\text { pervisão frouxa. } \\
\text { "Ciúme" de resultados, recompensas, relacionamentos e de visi- } \\
\text { bilidade. } \\
\text { Obstáculos operacionais } \\
\text { Interdependência: dificuldades em conseguir recursos humanos } \\
\text { qualificados e apoio. } \\
\text { Definir sistemas e processos para apoiar projeto. }\end{array}$ \\
\hline $\begin{array}{l}\text { G4: Controlar. } \\
\text { No olho do furacão. É aquela coisa de } \\
\text { tentar minimizar. }\end{array}$ & $\begin{array}{l}\text { Conflitos de interesses e psicológicos } \\
\text { Desejo de ser reconhecido e visibilidade. } \\
\text { "Ciúme" de resultados. } \\
\text { Obstáculos operacionais } \\
\text { Resultados intangíveis: dificuldade de medir (avaliação qualitati- } \\
\text { va). } \\
\text { Dificuldade de cumprir prazos (pressão, excesso de trabalho). }\end{array}$ \\
\hline $\begin{array}{l}\text { G5: Finalizar atividades e aquisições. } \\
\text { Está bom! Vamos pegar de volta. } \\
\text { E agora, José? }\end{array}$ & $\begin{array}{l}\text { Conflitos de interesses e psicológicos } \\
\text { Desejo de ser reconhecido (pela “missão cumprida") e de possível } \\
\text { promoção. } \\
\text { Ampliar espaços de poder (ao absorver logo as atividades do pro- } \\
\text { jeto). } \\
\text { "Ciúme" das atividades. } \\
\text { Obstáculos operacionais } \\
\text { Falta de política de realocação das pessoas após projeto. }\end{array}$ \\
\hline
\end{tabular}

Quadro 4 - Fontes de conflitos e de obstáculos operacionais nos processos de gestão de projetos

O Quadro 4 sintetiza os conflitos - classificados segundo as fontes de Chanlat (1996) - e obstáculos operacionais percebidos pelos entrevistados nos cinco grupos de processos de gestão de projetos. Assim, os processos de gestão de projetos contêm conflitos associados a mudanças de valores e comportamentos, a disputas por recompensas e a ciúmes. Obstáculos operacionais relacionam-se à falta de envolvimento do patrocinador, ao acesso a recursos, à pressão sobre a equipe do projeto e a dificuldades de formação de equipe.

Estes elementos são evidenciados por parte dos entrevistados ao apontarem os choques provocados durante o processo e que resultaram em sofrimento para os indivíduos (CLEGG; KORNBERG, PITSIS, 2008).

Assim, os conflitos que são de ordem natural nas organizações passam a ter seus efeitos negativos potencializados e sua solução se dá por meio do poder e da construção da negociação "política" patrocinada pelos gestores (HALL, 2004; BOLMAN; DEAL, 2008; DAFT, 2008; CLEGG; KORNBERGER, PITSIS, 2008; MORGAN, 1986; PFEFFER, 1994).

Mapear o surgimento de tais elementos durante o processo é uma questão que os autores supracitados afirmam demandar habilidades e competências do líder de projeto estratégico, mas que nem sempre está presente. Porém, em alguns casos, o problema não é a inexistência de tais habilidades ou competências, mas como observado, da autonomia para o exercício do poder e da atividade política (CLELAND; IRELAND, 2002; VALERIANO, 2005; VARGAS, 2005; KERZNER, 2006). 


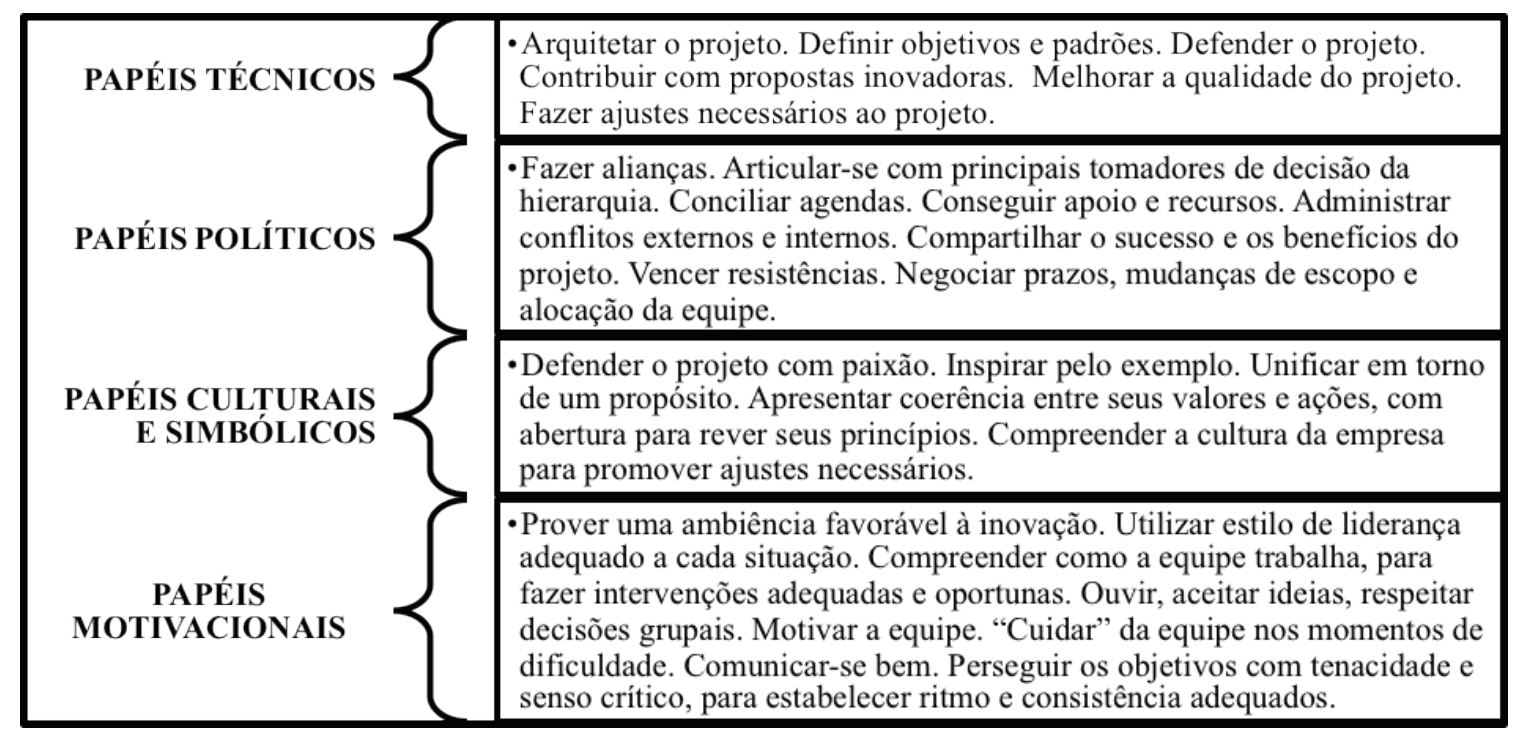

Figura 2 - Papéis desempenhados por líderes de projetos inovadores

Esta pesquisa não teve por objetivo identificar as funções dos líderes de projetos inovadores. No entanto, os entrevistados destacaram papéis cruciais dos líderes para vencer os conflitos e obstáculos operacionais, os quais foram agrupados em quatro categorias (Figura 3): técnicos, políticos, culturais e simbólicos e motivacionais.

Diferentemente da ênfase nos aspectos técnicos nos manuais do PMI (2008), observa-se que os papéis políticos, por estarem diretamente associados aos conflitos e às negociações para superar os obstáculos operacionais verificados na definição dos escopos dos projetos, assumem aspecto crucial para o líder de gestão de projetos no $\mathrm{BD}$, conforme os resultados apresentados nesta seção. Vale ressaltar que, como mostra a Figura 2, além da capacidade política dos líderes, os papéis técnicos, culturais, simbólicos e motivacionais são relevantes para a gestão eficaz de projetos inovadores.

\section{CONSIDERAÇÕES FINAIS}

Este artigo respondeu à pergunta de pesquisa ao explorar como conflitos e obstáculos operacionais se manifestam no ciclo de vida da gestão de projetos inovadores, segundo a percepção de líderes e consultores de projetos em um banco de desenvolvimento (BD). Adicionalmente, identificaram-se os papéis dos líderes na gestão dos projetos.

Os resultados evidenciaram conflitos de diversas naturezas em todos os grupos de processos da gestão de projetos e, com maior frequência, entre as equipes dos projetos e a estrutura hierárquica estabelecida, e não internamente nas equipes. A capacidade de vencer obstáculos operacionais também se mostrou crucial para o sucesso na elaboração e implantação de projetos inovadores, especialmente obstáculos operacionais relacionados com a definição do escopo. Conclui-se que conflitos e obstáculos operacionais são intrínsecos a projetos inovadores, de modo que a capacidade política, não somente para solucionar conflitos eventuais, é essencial para a eficácia de líderes de projetos.

A segmentação de fenômenos organizacionais em conflitos e obstáculos operacionais não foi tarefa simples, porque se observou que um conflito pode dar origem a um obstáculo operacional e vice-versa. Houve dificuldade, também, na classificação dos conflitos, pois estes 
podem ter origem diversa daquela que as pessoas professam; como disse um dos entrevistados: "uma pessoa pode expressar um conflito de valor para esconder um conflito de interesse". Além disso, conflitos de natureza diversa podem ocorrer em uma única situação (CHANLAT, 1996), em que há choques, como quando, por exemplo, as pessoas buscam visibilidade e reconhecimento (conflitos psicológicos e de interesse).

Projetos portadores de inovação apresentaram os três tipos de conflitos da classificação de Chanlat (1996) - conflitos de valores, conflitos de interesses e conflitos psicológicos. Confirmaram-se as previsões de Zaltman, Dunkan e Holbek (apud HALL, 2004) quanto às dificuldades de implantação de inovações com incerteza e complexidade elevadas, sem base científica sólida e clareza sobre os resultados.

Foram recorrentes conflitos relacionados à mudança na essência do $\mathrm{BD}$, que suscitou choque de valores referentes aos objetivos (nova maneira de pensar o desenvolvimento regional), ao estilo de liderança (supervisão próxima $x$ supervisão frouxa), à avaliação de desempenho (resultados tangíveis $x$ intangíveis) e ao status (hierarquia $x$ equipe do projeto).

Conflitos de valores manifestaram-se nos três primeiros grupos de processos, em relação à missão, ao modo de atuação, ao estilo de liderança (próxima $x$ frouxa) e à forma de avaliação de resultados do BD. A gestão desses conflitos é pouco explorada nos manuais de gestão de projetos, talvez com base na ideia de que a formação e a mudança de valores e comportamentos empresariais cabem, preponderantemente, aos fundadores e líderes das empresas (SCHEIN, 2004) ou porque a mudança cultural pode ser um processo mais longo que a implantação de um projeto. Entretanto, segundo os entrevistados, quando mudanças propostas atacam valores da empresa e exigem nova forma de pensar sobre sua missão, o líder do projeto deveria possuir a capacidade de desvendar esses valores e, pelo menos, iniciar adaptações necessárias.

"Ciúme" foi o termo usado por entrevistados para expressar um sentimento percebido frequentemente na gestão de projetos inovadores; ou seja, o "ciúme" influenciou o comportamento das pessoas no BD e manifestou-se em diversas situações e formas: pela não autoria de uma ideia, pelas recompensas de outrem (financeiras, relacionamentos, visibilidade), pela desqualificação do projeto, pela proteção de espaço (medo de perda), pela "minimização" de resultados e pela responsabilização pelas atividades (posse). Segundo TOMEI (1994, p. 6), o ciúme é primo-irmão da inveja e ocorre em "uma situação que envolve três pessoas, na qual a terceira pessoa retira, ou lhe é dado, 'o bom' que por direito pertence ao indivíduo ciumento". Observa-se que essas manifestações mais se aproximam do significado de "inveja", "um sentimento desagradável causado pelo desejo de ter aquilo que o outro possui, como a riqueza, o poder, o status social, o amor, a beleza", a qual "pode suscitar sentimentos de frustração, de cólera, de piedade por si mesmo, de cobiça e de reivindicação" (DE VRIES, 1996, p. 73). A distinção entre "inveja" e "ciúme" é pouco clara do ponto de vista prático (DE VRIES, 1996). O que importa é que ambos, presentes nos processos de gestão de projetos, exigem capacidade do líder de percebê-los e administrá-los convenientemente (TOMEI, 1994; DE VRIES, 1996).

A perícia técnica mostrou-se essencial para conferir credibilidade e legitimidade ao líder do projeto perante sua equipe e a empresa, conforme defendem Zaltman, Dunkan e Holbek (apud HALL, 2004), assim como para suavizar, pelo menos, ataques às ideias do projeto (PFEFFER, 1994), embora Graham e Englund (1997) não a considerem necessária. De fato, as pessoas no BD esperam que o líder de um projeto inovador saiba desempenhar um conjunto de papéis "técnicos" (expressos na Figura 3); para tanto, precisa de conhecimento que lhe permita, em discussões de natureza operacional, defender o projeto e promover ajustes. Como disse um dos entrevistados, "muitas vezes, a diferença entre tomadores de decisão eficazes e medíocres é que 
os primeiros não aceitam a primeira alternativa que lhes vem à cabeça; em vez disso, continuam a cavar, até encontrar a melhor solução".

Os entrevistados reservam ao líder do projeto papéis "simbólicos" relevantes - defender o projeto com paixão, inspirar pelo exemplo, unificar em torno de um propósito, por exemplo -, que se enquadram na perspectiva simbólica de Bolman e Deal (2008), segundo a qual o desafio da liderança é inspirar e criar fé, beleza e significado.

Capacidade de motivar a equipe revelou-se essencial em todo o ciclo da gestão de um projeto inovador. Dentre os papéis "motivacionais" do líder de projeto, os entrevistados destacaram, primeiramente, a comunicação com a equipe e com a empresa, a qual requer perspicácia para compreender, além da palavra e da escrita, sinais carregados de significados e sutilezas em usar ou não sua equipe na comunicação. O segundo papel de destaque refere-se ao que Bolman e Deal (2008) chamaram "cuidar" das pessoas. Nas experiências relatadas, esse papel consiste em compreender e satisfazer as necessidades dos membros da equipe nos momentos de desânimo, frustração, isolamento, ataque, desconfiança, desqualificação, indiferença, retaliação, excesso de trabalho, pressão e baixa produtividade vivenciados no desenvolvimento do projeto. Nesse aspecto, o líder deve cuidar de si mesmo também.

A análise permitiu ver que obstáculos operacionais estiveram relacionados com planejamento (especialmente o detalhamento do escopo), obtenção de recursos, definição de processos e elaboração de sistemas para dar suporte à implantação de projetos inovadores. Esses obstáculos representaram severas restrições ao desenvolvimento de projetos, comprometendo prazos, custos e qualidade. Apesar de melhorias em conhecimento e uso de ferramentas (softwares) para auxiliar os processos de gestão de projetos, obstáculos operacionais parecem repetir-se como antes na estrutura hierárquica tradicional: se o projeto é gerido com dedicação exclusiva de uma equipe, a hierarquia (permanente) ainda mantém o controle de recursos (humanos, financeiros, tecnológicos e relacionais) requeridos pelo projeto. Assim, na formação da equipe do projeto estratégico, a escolha do líder na organização reveste-se de caráter mais político que técnico; já a escolha dos demais membros da equipe depende da vontade da hierarquia, que nem sempre libera pessoas capacitadas, de modo que recomendações do modelo de gestão de projeto parecem inócuas nesse aspecto.

O mapeamento dos conflitos e obstáculos operacionais mostrou que a capacidade política para administrar com poder, não apenas para solucionar conflitos eventuais, bem como a capacidade para administrar "ciúmes" ou "inveja", constitui requisito essencial dos líderes de projetos inovadores e deve merecer mais estudos para aperfeiçoamento e eficácia em gestão de projetos. Assim, torna-se necessária a capacidade do líder de projeto estratégico para o exercício do poder e da atividade política, a fim de, por exemplo, influenciar decisões, conseguir aliados e recursos, vencer as resistências e, por fim, alcançar os objetivos do projeto. Para Pfeffer (1994), o uso do poder não representa a única maneira de atingir objetivos e solucionar conflitos, mas um importante caminho.

Em razão da metodologia adotada, com uma escolha intencional e reduzida de entrevistados, os resultados desta investigação apresentam limitações: não podem ser generalizados para outras empresas. Além disso, a coleta de dados não contemplou membros da estrutura hierárquica da empresa, mas somente líderes e consultores de equipes de projetos inovadores.

Futuras pesquisas poderão abordar o grau de exigência do exercício de funções políticas por parte do líder de projeto, já que essa função parece ser crucial para lidar com conflitos, além de ter sido pouco explorada pela literatura pesquisada em gestão de projetos. 


\section{REFERÊNCIAS}

BARDIN, L. Análise de conteúdo. Lisboa: Edições 70, 2008.

BARNEY, J.; WRIGHT, M.; KETCHEN, D. The resource-based view of the firm: ten years after 1991. Journal of Management, v. 27, p. 625-641, 2001.

BOLMAN, L. G.; DEAL, T. E. Reframing organizations: artistry, choice, and leadership. $4^{\text {th }}$ ed. San Francisco, CA: Jossey-Bass, 2008.

CARVALHO, A.B.; ABREU, I.M.C. de; PEDROZO, I.F. Fluxograma como ferramenta de aperfeiçoamento e de controle em instituições públicas. Revista de Administração da UFSM, v.6, n.2, p.373-394, 2013.

CARVALHO, M. M. de; RABECHINI Jr., R. Construindo competências para gerenciar projetos: teoria e casos. São Paulo: Atlas, 2005.

CARVALHO, M. M. de; RABECHINI Jr., R. Perspectivas da gestão de projetos. In: RABECHINI Jr., R.; CARVALHO, M. M. de. (org.). Gerenciamento de projetos na prática: casos brasileiros. São Paulo: Atlas, 2006. cap. 1, p. 1-24.

CHANLAT, Jean-François. Conflict and politics. In:WARNER, M. (ed.). International encyclopedia of business \& management. London: Routledge, 1996, p. 711-719.

CLEGG, S.; KORNBERGER, M.; PITSIS, T. Managing and organizations. $2^{\text {nd }} \mathrm{ed}$. Thousand Oaks, CA: Sage Publications, 2008.

CLELAND, D. I.; IRELAND, L. R. Gerência de projetos. Rio de Janeiro: Reichmann \& Affonso, 2002.

COOPER, D. R.; SCHINDLER, P. S. Métodos de pesquisa em administração. 7. ed. Porto Alegre: Bookman, 2003.

CRESWELL, J. W.; CLARK, V. L. P. Designing and conducting mixed methods research.
Thousand Oaks, CA: Sage Publications, 2007.

DAFT, R. L. Organizações: teoria e processos. 2. ed. São Paulo: CENGAGE Learning, 2008.

DE VRIES, M. F. R. K. A inveja, grande esquecida dos fatores de motivação em gestão. In: CHANLAT, J. F. $O$ indivíduo na organização: dimensões esquecidas. 3. ed. São Paulo: Atlas, 1996, p. 67-82.

DUARTE, C.C.M.; BIANCOLINO, C.A.; STOROPOLI, J.E; RICCIO, E.L. Análise do conceito de sucesso aplicado ao gerenciamento de projetos de tecnologia da informação. Revista de Administração da UFSM, v.5, n.3, p.459478, 2012.

DRUCKER, P. Sociedade pós-capitalista. São Paulo: Pioneira Thomson Learning, 2002.

FERREIRA, A. B. de H. Novo dicionário da língua portuguesa. 2. ed. Rio de Janeiro: Nova Fronteira, 1989.

FLICK, U. Introdução à pesquisa qualitativa. 3. ed. Porto Alegre: Artmed, 2009.

GIDO, J.; CLEMENTS, J. P. Gestão de projetos. São Paulo: Thomson Learning, 2007.

GRAHAM, R. J.; ENGLUND, R. L. Creating an environment for successful projects: the quest to manage project management. San Francisco, CA: Jossey-Bass, 1997.

HAIR Jr., J. F. et al. Fundamentos de métodos de pesquisa em administração. Porto Alegre: Bookman, 2005.

HALL, R. H. Organizações: estruturas, processos e resultados. 8. ed. São Paulo: Prentice Hall, 2004.

$\mathrm{HATCH}$, M. J. Organization theory: modern, symbolic and postmodern perspectives. Oxford: Oxford, 1997.

ISO-INTERNATIONAL ORGANIZATION FOR STANDARDIZATION. ISO 10006: 2003. 2. ed. Quality management systems - guidelines for 
quality management in projects.

$\begin{array}{llllllllll}J & \mathrm{~A} & \mathrm{~N} & \mathrm{O} & \mathrm{W} & \mathrm{I} & \mathrm{C} & \mathrm{Z} & -\end{array}$ PANJAITAN,M.;NOORDERHAVEN,N.G. Trust, calculation, and interorganizational learning of tacit knowledge: an organizational roles perspective. Organization Studies, v. 30, n. 10, p. 1021-1043, 2009.

JULIEN, P. A. Empreendedorismo regional e a economia do conhecimento. São Paulo: Saraiva, 2010.

KERZNER, H. Gestão de projetos: as melhores práticas. 2. ed. Porto Alegre: Bookman, 2006.

KOTTER, J. Liderando mudança. Rio de Janeiro: Campus, 1997.

KRIPPENDORFF, K. Content analysis: an introduction to its methodology. $2^{\text {nd }}$ ed. Thousand Oaks, CA: Sage Publication, 2004.

LINDBLOM, C. E. The science of munddling through. Public Administration Review, v. 19, n. 2, p. 79-78, 1959.

MAXIMIANO, A. C. A. Administração de projetos: como transformar idéias em resultados. 2. ed. São Paulo: Atlas, 2006.

MINTZBERG, $H$. The design school: reconsidering the basic premises of strategic planning. Strategic Management Journal, v. 11, p. 171-195, 1990.

MINTZBERG, H. Patterns in strategy formation (in strategy formulation). Management Science, v. 24, n. 9, p. 934-948, 1978.

MORGAN, G. Images of organization. Newbury Park, CA: Sage Publications, 1986.

PFEFFER, J. Managing with power: politics and influence in organizations. Boston, MA: Harvard Business School Press, 1994.

PFEFFER, J.; SALANCIK, G. R. The external control of organizations: a resource dependence perspective. Stanford, CA:
Stanford University Press, 2003.

PFEIFFER, P. Gerenciamento de projetos de desenvolvimento: conceitos, instrumentos e aplicações. Rio de Janeiro: Brasport, 2005.

PMI-Project Management Institute. A guide to the Project Management Body of Knowledge (PMBOK). 4. ed. Project Management Institute, 2008.

PORTER, M. E. A vantagem competitiva das nações. Rio de Janeiro: Campus, 1993.

RABECHINI Jr., R.; CARVALHO, M. M. de. (org.). Gerenciamento de projetos na prática: casos brasileiros. São Paulo: Atlas, 2006.

RASCHE, A.; CHIA, R. Researching strategy practices: a genealogical social theory perspective. Organization Studies, v. 30, n. 7, p. 713-734, 2009.

RICHARDSON, R. J. e Colaboradores. Pesquisa social: métodos e técnicas. 3. ed. São Paulo: Atlas, 1999

SCHEIN, E. H. Organizational culture and leadership. $3^{\text {rd }}$ ed. San Francisco, CA: JosseyBass, 2004.

SILVA, F.A.; GONÇALVES, C.A. O processo de formulação e implementação de planejamento estratégico em instituições do setor público. Revista de Administração da UFSM, v.4, n.3, p.458-476, 2011.

TOMEI, P. M. Inveja nas organizações. São Paulo: Makron Books, 1994.

VALERIANO, D. Moderno gerenciamento de projetos. São Paulo: Prentice Hall, 2005.

VARGAS, R. Gerenciamento de projetos: estabelecendo diferenciais competitivos. 6 . ed. Rio de Janeiro: Brasport, 2005.

WEBER, M. Conceitos básicos de sociologia. São Paulo: Moraes, 1987.

WEBER, M. Economía y sociedad: esbozo de sociología comprensiva. México: Fondo de 
Cultura Económica, 1987.

WEICK, K. E. Sensemaking in organizations.

Thousand Oaks: Sage Publications, 1995.

WYSOCKI, R. K. et al. Effective project

management: traditional, agile, extreme. $5^{\text {th }}$ ed. New York, NY: Wiley Publishing, 2009.

YIN, R. K. Estudo de caso: planejamento e métodos. 3. ed. Porto Alegre: Bookman, 2005. 